\title{
Assessment of Total Attenuation and Adaptive Scheme for Quality of Service Enhancement in Tropical Weather for Satellite Networks and 5G Applications in Nigeria
}

\author{
Joseph. S. Ojo ${ }^{1}$ (i), Elijah .O. Olurotimi ${ }^{2}$ (D), Obiseye.O. Obiyemi ${ }^{3}$ (i) \\ ${ }^{1}$ Department of Physics, Federal University of Technology, Akure, 340001, Nigeria, josnno@yahoo.com \\ ${ }^{2}$ Department of Electronic Engineering, Durban University of Technology, KZN, 4000, South Africa, \\ elisayrot@gmail.com \\ ${ }^{3}$ Department of Electrical and Electronic Engineering, Osun State University, Nigeria, obiseyeobi@gmail.com
}

\begin{abstract}
The dynamic weather condition is a major concern for optimum channel utilization in recent times, especially at higher frequencies with larger bandwidth for $5 \mathrm{G}$ applications. Over the years, rain-induced attenuation among the hydrometeors has been linked as the major cause of signal impairment especially at the frequency, $f \geq 10 \mathrm{GHz}$. However, when $f>18 \mathrm{GHz}$, the significant impact of other hydrometeors; cloud/fog, and scintillation increases tremendously, especially for Low Earth Orbit, LEO satellites. LEO satellites find applications in fibre optics technology, scientific research, remote sensing, surveillance, meteorology, satellite imaging, and other applications. In this paper, the assessment of combined impairments based on 5-year (2012-2016) data has been carried out and a dynamic adaptive intelligent scheme (DAIS) has been adopted to achieve a good quality of service along the satellite channels operating at $\mathrm{Ku}-\mathrm{V}$ band frequencies over five stations representing different climatic regions in Nigeria namely: Port Harcourt (PH), Akure, Ilorin, Zaria, and Kano. The proposed DAIS based on fuzzy logic was able to achieve a significant reduction in the transmitting power by about $70 \%$ and SNR by $50 \%$ across the frequencies considered without altering the information content of the downlink parameters, thereby improving the QoS significantly and adhere to Customer Service Level Agreements (CSLAs) irrespective of the weather dynamics. The overall results show that the adaptive intelligent techniques can effectively fix signal links under the dynamic weather conditions for both satellite and wireless networks in this region. Information from the results is timely because it will serve as the bedrock for the newly launched transformation to the digital video broadcasting (DVB) system in Nigeria for effective service delivery.
\end{abstract}

Index Terms - Total attenuation, Adaptive scheme, QoS enhancement, Satellite networks, Digital video broadcasting, Dynamic tropical weather.

\section{INTRODUCTION}

Quality of Service (QoS) is a tool for determining the level of efficiency of a good network; though regarded as a complex function because it primarily depends on four factors namely: packet delivery ratio, throughput, jitter, and end-to-end delay [1]. These primary factors are time-dependent that can 
be influenced by some internal factors and must be fixed as a single unit. Thus, the problem of attenuation on terrestrial and satellite communication links can significantly affect the QoS, especially with the recent demand for wide bandwidth and higher frequency bands $(\mathrm{K}, \mathrm{Q}$, and $\mathrm{V})$. The attenuation problem becomes particularly pronounced at frequencies above $10 \mathrm{GHz}$ [2]-[6].

The propagation paths between the ground-based station (link below the rain height, $L_{s}$ ) and the earth-space path $\left(L_{e s}\right)$ are susceptible to strong degradation due to hydrometeors (fading, gaseous absorption, cloud, and fog-induced attenuations, and troposphere-based scintillation), which often leads to signal downtime. This assertion has been confirmed by many researchers over the years [7][12]. However, in recent times, especially at frequencies above $18 \mathrm{GHz}$, the significant impact of other hydrometeors; cloud, fog, and scintillation increase tremendously, especially for Low Earth Orbit, LEO satellite applications operating at low altitude and useful by most of the communication satellites as well as optical wavelengths that have applications in fibre optics technology.

Due to the aforementioned factors, among others, the capacity of the ground-based receiver is lost and this consequently affects the link [13]. This scenario arises due to the inability of the groundbased receiver to adequately accommodate the atmospheric impairments. Also, the receiver-hub could not automatically regulate the ground-based receiver along with the dynamic weather conditions. Thus, the need to determine a mitigation scheme for the combined rain-induced attenuation, cloudinduced attenuation, and scintillation due to rain along the $L_{s}-L_{e s}$ propagation path for satellite applications is crucial. Although, not only for good QoS alone, but owing to keep to the customer service level agreement (CSLA).

Several research efforts have been made to ascertain QoS based on total attenuation in the temperate region, with a few attempts in the tropical region despite the nature of weather conditions associated with the tropical environment, Nigeria inclusive. The tropical environment is characterized by high humidity and rainfall with more cloud cover as compared to the temperate climate. Among the research efforts worth mentioning is the [9] that adopted an empirical approach for the combined effects on total attenuation based on the simultaneous measurement from beacon and radiometer from a temperate region. The results indicated that the rain associated parameters accounted for the best average accuracy globally between 10 and $30 \mathrm{GHz}$. Another similar effort has earlier been made by [14], where a prediction of propagation parameters such as rain attenuation, site diversity gains, and interference by rain scattering was developed. A test of the model was performed using data collected in Europe with the satellites SIRIO and OTS. Other works based on data from temperate climates include the work of [4], [15]-[16] to mention but a few.

The few previous works on the subject matter where intelligent techniques were adopted in the tropical or subtropical regions for satellite applications does not consider the total attenuation. For example, [17], adopted an adaptive technique of a decision-based system to predict rain-induced attenuation over some locations in Nigeria. The results show a minimum fade margin that could be adopted for the uplink and downlink frequencies, especially at $99.5 \%$ availability for a worst-case 
situation at Ka-band frequency. However, only rain-induced attenuation was considered while other weather parameters were not put into consideration. Also, [18] adopted intelligent techniques to maintain QoS at a subtropical location, although in addition to rain attenuation, other extra fading like snow, gaseous absorption, cloud, and scintillation were considered. However, their performance was evaluated only through simulation and only one location was considered. The other related work by [5] did not adapt attenuation due to fog and additional effect due to atmospheric noise temperature with fibre optics. Besides, the work was performed based on subtropical data which may not apply to the tropical region.

This paper is aimed to adopt a dynamic adaptive intelligent scheme (DAIS) by introducing the noise figure-induced attenuation to the combined atmospheric impairments to assess their impact along the $L_{s}-L_{e s}$ propagation path. This will be achieved through interaction with power margin, propagation angle, feedback control on the uplink, and the downlink segment. These parameters will be utilized on higher modulations like Quadrature amplitude modulation-QAM and Quadrature Phase Shift Keying-QPSK scheme on satellite design. Higher modulation is needed in recent technologies especially, for $5 \mathrm{G}$ networks. The ITU model has a wide range of application conditions for estimating the CDF of the total impairments using time-based rain rate, cloud cover data, visibility data, and atmospheric parameters like temperature, relative humidity, pressure among others. In this paper, 5year (2012-2016) time series rain rate data have been used to deduce rain attenuation for Earth-space links applications over five stations representing different climatic regions in Nigeria namely: Port Harcourt (Coastal-C), Akure (Tropical Rain Forest-TRF), Ilorin (Sudan Savannah-SS), Zaria (Guinea Savannah-GS) and Kano (Sahel-S). Other data used also contained 5 years of achieved clouds cover data, visibility data, and other atmospheric parameters collected from the Nigerian Meteorological Agency (NIMET) Federal Ministry of Aviation, Oshodi Lagos, Nigeria.

Table 1 shows the characteristics of each of the study sites. The dataset was employed to study the total impairments on radio paths at centimeter and millimeter-wave frequencies using ITU models by applying DAIS on higher modulations QAM and QSPK. For the satellite applications, two geostationary satellites have been considered, namely: Eutelsat 36B (Ku-band, centimeter band) and Eutelsat 7A (Ka-band, millimeter band) as seen at each of the sites. The two satellites have been known to offer a 24-hour view over Sub-Saharan Africa among other regions for fixed satellite services (FSS), broadcasting satellite services (BSS), and multipoint applications. However, the coverage of the two satellites at each of the earth stations is susceptible to signal degradation due to impairments along the propagation paths, hence, requires appropriate prediction, and characterization of these channels becomes an issue of necessity.

The other parts of the paper are arranged as follows: section 2 briefly discusses the overview of different tropospheric impairments and the method adopted while section three provides detailed results and discussion obtained. Section five gives the conclusion and recommendations.

The paper is unique being the first statistical approach for assessing the combined impairments 
along the terrestrial and satellite propagation paths in Nigeria based on DAIS. DAIS will assist based on the appropriate modulation scheme to provide the meet the CSLAs.

TABLE I. CHARACTERISTICS OF EACH OF THE STUDY SITES

\begin{tabular}{lllcc}
\hline Climatic Region & Stations & Coordinates & Altitude (m) & Average Annual Rainfall (mm) \\
\hline Coastal (C) & Port Harcourt (PH) & $4.8156^{\circ} \mathrm{N}, 7.0498^{\circ} \mathrm{E}$ & 16 & 2708 \\
Tropical Rain Forest (TRF) & Akure & $7.2571^{\circ} \mathrm{N}, 5.2058^{\circ} \mathrm{E}$ & 350 & 1524 \\
Sudan Savannah (SS) & Ilorin & $8.4799^{\circ} \mathrm{N}, 4.5418^{\circ} \mathrm{E}$ & 307 & 1220 \\
Guinea Sudan (GS) & Zaria & $11.0855^{\circ} \mathrm{N}, 7.7199^{\circ} \mathrm{E}$ & 644 & 1050 \\
Sahel (S) & Kano & $12.0022^{\circ} \mathrm{N}, 8.5920^{\circ} \mathrm{E}$ & 488 & 697 \\
\hline
\end{tabular}

\section{Methodology}

To achieve optimum system performance, we have adopted propagation factors that include the overall prediction of fading namely: rain-induced attenuation, cloud attenuation, attenuation due to clouds/fog-based impairments, gaseous absorption, attenuation due to noise temperature, melting layer-based impairments, and tropospheric scintillations. We have not considered the ionospheric effect due to insignificant contributions to signal degradation of frequency above $10 \mathrm{GHz}$ [9]. Fig. 1 presents a typical scenario of total impairments along the Earth-space path.

\section{A. Tropospheric Impairments}

The ITU model has a wide range of application conditions and so it has been adopted for most of the predictions of the CDF of the overall impairments. [19] and [20] provided the series of stages needed to estimate the statistics of a continuing rain-induced degradation and the tropospheric clearair effect scintillation.

\section{A.1. The Lengthy Rain-based Attenuation}

The statistics of the rain-based attenuation on slant-path are estimated at each of the locations at the $\mathrm{Ku}-\mathrm{V}$-band frequencies by considering the following parameters: the point rainfall rate, $R_{0.01} \%$ in $\mathrm{mm} / \mathrm{h}$, the elevation angle- $\theta$, the height above mean sea level $(\mathrm{km})-h s$, the latitude of the earth station's latitude (degrees)- $\phi$. Others are the frequency, $f$ in $\mathrm{GHz}$, and the effective earth radius $(8500 \mathrm{~km}), R_{\text {eff. }}$

For the sake of paucity of space, not all the steps outlined in [20] for estimating rain-induced will be presented in this work. Other details are available on the recommendation. 


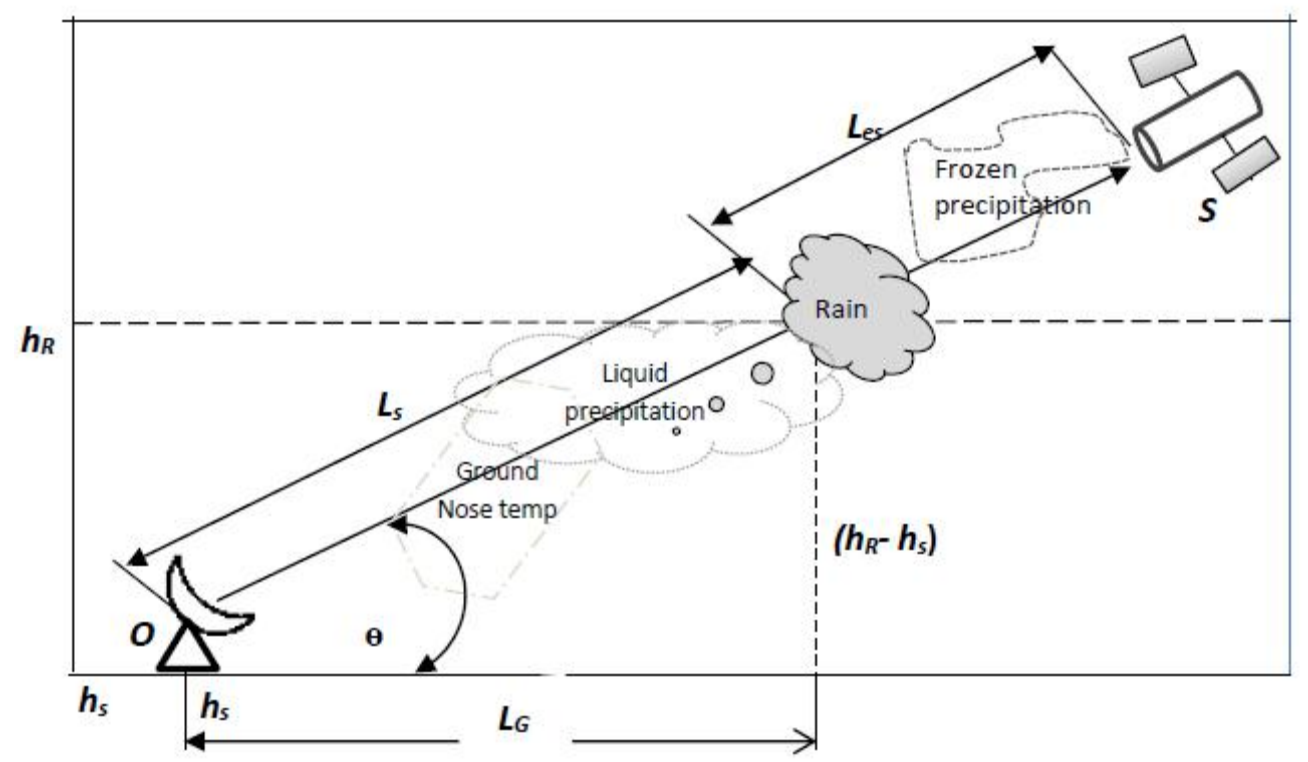

Fig. 1. A typical scenario of total impairments along Earth-space path.

The rain-based attenuation at $0.001 \%$ to $10 \%$ of an average period of observation is estimated using [19]:

$$
\text { Att }_{p}=A_{0.01}\left(\frac{p}{0.01}\right)^{-\left[0.655+0.033 \ln (p)-0.045 \ln \left(A_{0.01}\right)-w \sin \theta(1-P)\right]}
$$

where $p$ is between interest $0.001 \%$ and $10 \%$ and $w$ is represented as:

$$
w=0 \text { when } p \geq 1 \% \text {, }
$$

while for $p<1 \%$

$$
w=0 \quad \text { for }|\Phi| \geq 36^{0}
$$

$$
w=-0.005(|\Phi|-36) \quad \text { for } \theta \geq 25^{\circ} \text { and }|\phi|<36^{\circ}
$$

and

$$
w=-0.005(\Phi-36)+1.8-4.25 \sin \theta, \quad \text { when } \theta<25^{\circ} \text { and }|\Phi|<36^{0 o}
$$

\section{A.2. Clear Air Effect-Tropospheric Scintillation}

The rapid fluctuation in the amplitude that arises due to the changes in the gradient of the tropospheric refractive index is referred to as scintillations based on the troposphere, $A_{s}$. The scintillation values can be influenced by the gradual reduction in antenna beam-width, a gradual reduction in elevation angle of the station, and increment in the station frequency [20] also provided the procedure for estimating tropospheric scintillations. The fade depth due to tropospheric scintillations, $A_{t s}(p)$, for the $\mathrm{p} \%$ unavailability of the signal is estimated using [19]:

$$
A_{t s}(p)=a(p) \cdot \sigma_{s}
$$

where $a(p)$ is the time percentage factor for the percentages range between $0.01 \%$ and $50 \%$, and $\sigma_{s}$ is the standard deviation of the fluctuation in the amplitude of the signal. 


\section{A.3. Fading due to Noise Temperature}

Due to the increase in attenuation as frequency increases, the emitted noise from the earth station also increases. This increase may influence the signal to noise ratio, especially for the stations with low noise front-ends. Hence, the total attenuation based on the noise figure-induced attenuation, Atnf in $(\mathrm{dB})$ can be estimated using [19]:

$$
A_{\text {tnf }}=10 \times 10 \log \left(\frac{T_{s k y}}{T_{r e f}}\right)
$$

where $T_{r e f}$ is $290 \mathrm{~K}$ and $T_{s k y}$ is the fading due to noise temperature in Kelvin.

\section{A.4. Gaseous Absorption}

Attenuation based on atmospheric gases arises from the abundance of oxygen and water vapor in the atmosphere. The attenuation due to dry-air $A_{o}$, often known as the absorption due to atmospheric oxygen is strongly influenced by the pressure and air temperature in the atmosphere, while the water vapour-induced attenuation, $A_{w v}$ is strongly influenced by the air temperature. Details are stated in [22] and are not re-iterated here due to the paucity of the space.

\section{A.5. Clouds and Fog-induced Attenuation}

Clouds and fog-induced attenuation, $A_{c f}$ are influenced by the air temperature and liquid water content in the atmosphere (parameter which cannot easily be measured). However, [23] revealed that $A_{c f}$ can be estimated from temperature and relative humidity profiles (as measured by radiosonde) using:

$$
\mathrm{A}_{\mathrm{cf}}=\frac{0.4095 f L}{\varepsilon^{\prime \prime}\left(1+\eta^{2}\right) \sin (\theta)}(\mathrm{dB})
$$

The parameters $f$ is the frequency in $\mathrm{GHz}, L$ is the cloud thickness, equal to $1 \mathrm{~km}, \theta$ is the elevation angle, $\eta=\left(2+\varepsilon^{\prime}\right) / \varepsilon^{\prime \prime}$, and $\varepsilon^{\prime}$ and $\varepsilon^{\prime \prime}$ are the real and imaginary parts of the permittivity of water respectively [9].

Hence, the total attenuation, $A_{T}$ of the combine impairments is given as [19]:

$$
A_{T}(p)=A_{t t}(p)+A_{w v}(p)+\sqrt{A^{2}(p)+A_{t s}^{2}(p)+A_{t n f}{ }^{2}}(\mathrm{~dB})
$$

where $A^{2}(p)=\left(A_{p}(p)+A_{c f}(p)\right)^{2}$.

Equations (1) to (7) are processed using Matlab 2017a gaspl function to obtain the total impairments on radio wave signals for the studied locations.

\section{B. Signal to Noise Ratio (SNR)}

The magnitude of the strength of radio signals concerning fading and the noise generated from the noise is termed SNR. It can be deduced using [24]:

$$
S N R=\frac{P_{t} G_{t} G_{c}}{K T B_{w} A_{t n f} L_{s y s}}\left(\frac{\lambda_{0}}{4 \pi d}\right)^{2}
$$


where $G_{t}$ is the gain of the transmitting antenna, $G_{r}$ is the gain of the receiving antenna, $P_{t}$ is the power transmitted in $\mathrm{W}$. The wavelength in free-space is represented as $\lambda_{0}(\mathrm{~m})$, and $K$ is the Boltzmann constant with value $1.38 \times 10^{-23} \mathrm{~J} / \mathrm{K}$. The absolute temperature is denoted as $T(\mathrm{~K}), B_{w}$ is the bandwidth (Hz), while $F$ is the noise factor (unit-less) is The system loss (Atmospheric loss + total attenuation + Polarizer loss) in a ratio (unit-less) is also denoted as $L_{s y s}$, and $d$ is the range (m). The noise factor $(F)$ can be deduced using [24]:

$$
F=10 \log Y
$$

where $Y=1+$ rain noise/ambient temperature.

For this work as related to digital communication, the SNR will be determined based on a bit energy-to-noise ratio $E_{b} / N_{o}$. It is referred to as the magnitude of the SNR for a digital communication system. $E_{b} / N_{o}$, determine the effectiveness of a signal for digital communication at a specified bandwidth. For satellite applications as one of the objectives of this study, the transmitting side of the satellite is measured in terms of the equivalent isotopically radiated power (EIRP) and the figure of merit (G/T). Hence, equation (8) is equivalent to ratio $E_{b} / N_{o}$ as [17], [24]-[26]:

$$
\left.S N R=E_{b} / N_{o}(d B)=E I R P+G / T(d B / T)-A_{t n f}(d B)-L_{s y s}-10 \log R_{B}(d B)\right)
$$

where $R_{B}$ is the bit rate and all other terms retain the usual meaning. We have adopted the method employed in the work of [25] to make provision for the adjustment in $S N R$ to achieve optimum system performance based on DAIS. For this study, the simulation has been carried out for radio links at Ku$\mathrm{V}$ bands at different slant paths and stations' elevation angles depending on the site based on Eutelsat 36B (Ku-band), Eutelsat 7A (Ka bands) Geostationary satellite located in its service footprint covers each of the sites adequately and frequency scaling for the V-band frequency. Tables 2 and 3 present the specifications of each of the satellites and the site configurations for $\mathrm{Ku}$ and Ka-band respectively.

\begin{tabular}{|c|c|c|c|c|c|}
\hline Stations & $\mathrm{PH}$ & Akure & Ilorin & Zaria & Kano \\
\hline \multicolumn{6}{|c|}{ Description/Specifications } \\
\hline Satellite position & \multicolumn{5}{|c|}{36.009 E, $323.991 \mathrm{~W}$} \\
\hline Elevation (degree) & 55.95 & 52.51 & 52.22 & 54.82 & 55.25 \\
\hline Azimuth (degree) & 98.49 & 102.30 & 103.62 & 109.54 & 111.76 \\
\hline Sea level $(\mathrm{km})$ & 0.016 & 0.350 & 0.307 & 0.644 & 0.488 \\
\hline Polarization & $\mathrm{H}$ & $\mathrm{H}$ & $\mathrm{H}$ & $\mathrm{H}$ & $\mathrm{H}$ \\
\hline Slant path $(\mathrm{km})$ & 36728 & 36925 & 36942 & 36791 & 36767 \\
\hline Satellite delay (ms) & 244.9 & 246.2 & 246.3 & 245.3 & 245.1 \\
\hline
\end{tabular}

TABLE II. SPECIFICATION OF THE 12.245 GHZ LINK FOR EUTELSAT 36B SATELLITE LINK [27]

TABLE III: SPECIFICATION OF THE 12.751 GHZ LINK FOR EUTELSAT 7A SATELLITE LINK [27]

\begin{tabular}{lccccc}
\hline \multicolumn{1}{c}{ Stations } & PH & Akure & Ilorin & Zaria & Kano \\
\cline { 1 - 3 } Description/Specifications & & & & & \\
Satellite position & & & 7.028 E, 352.972 W & \\
Elevation (degree) & 84.44 & 80.56 & 79.55 & 77.01 & 75.78 \\
Azimuth (degree) & 181.73 & 162.52 & 163.84 & 183.67 & 187.15 \\
Sea level (km) & 0.016 & 0.350 & 0.307 & 0.644 & 0.488 \\
Polarization & $\mathrm{H}$ & $\mathrm{H}$ & $\mathrm{H}$ & $\mathrm{H}$ & $\mathrm{H}$ \\
Slant path (km) & 35812 & 35860 & 35876 & 35925 & 35953 \\
Satellite delay (ms) & 238.7 & 239.1 & 239.2 & 239.5 & 239.7 \\
\hline
\end{tabular}




\section{Optimization based on DIAS}

To optimize the link availability and queuing characteristics for good QoS along the Earth -space over the study sites, we have adopted DAIS based on the Adaptive Neuro Inference System (ANIFIS)-Fuzzy logic scheme on additive white Gaussian noise (AWGN) channel. AWGN has been used because it shows the actual relationship between SNR and data rate achievable based on the expected bit error rate (BER). Fuzzy logic is a set-associated tool represented using a Membership Function (MFn). The MFn defines a scenario whereby a typical input within a space is linked to a set of values between 0 and 1 based on curves. MFn also assigns different levels of membership to an element within a universal set.

The principle of fuzzy logic is based on IF/THEN rules to propose a logical statement. The knowledge base accommodates the logical rules while the fuzzy inferencing is done with the stored rules [13]. The DAIS will iteratively interact with the assigned parameters, in this case, the angle of propagation, frequency, size of the frame, the calculated SNR among other values) to activate the appropriate modulation to its threshold level, based on the location-based weather conditions, configuration settings, and tolerance margins of the system [18].

Depending on the ratio of the value of the signal to noise obtained, DIAS will either raise the power transmitted or jump to the next step. This step will keep looping until an appropriate value is obtained. Hence, DIAS has the capabilities to regulate the data rate, frequency, and frame size so that the SNR can be adjusted, especially under unpredicted propagation impairments conditions; by using the refresh button in the first stage as depicted in Fig. 2. The interaction using fuzzy logic was simulated based on the MATLAB/SIMULINK package. Fig. 3 presents a block diagram of the proposed description of each set of fuzzy rule schemes adopted for the DAIS. All the possible rules needed for the optimization were written, membership functions were formed and simulations were carried out.

In summary, the stages involved include: creating a database based on input/output pairs, formulation of rules for each of the data pair using the appropriate mode and number of fuzzy sets, removing the conflicting rules, creating the inference engine, and the decision stage. The overall results when applied to the QPSK and QAM modulation schemes will recommend an appropriate maximum BER for QoS. QAM and QPSK are adopted as the modulation schemes for the optimization because of their efficiency in dynamically allocating capacity, simple to implement, and have the lowest peak-to-average power ratio and requiring minimal power amplifier back-off [28]. Fig. 2 presents a DAIS interrelated algorithm to achieve optimum, and efficient QoS on satellite networks under different propagation impairments based on improving SNR. 


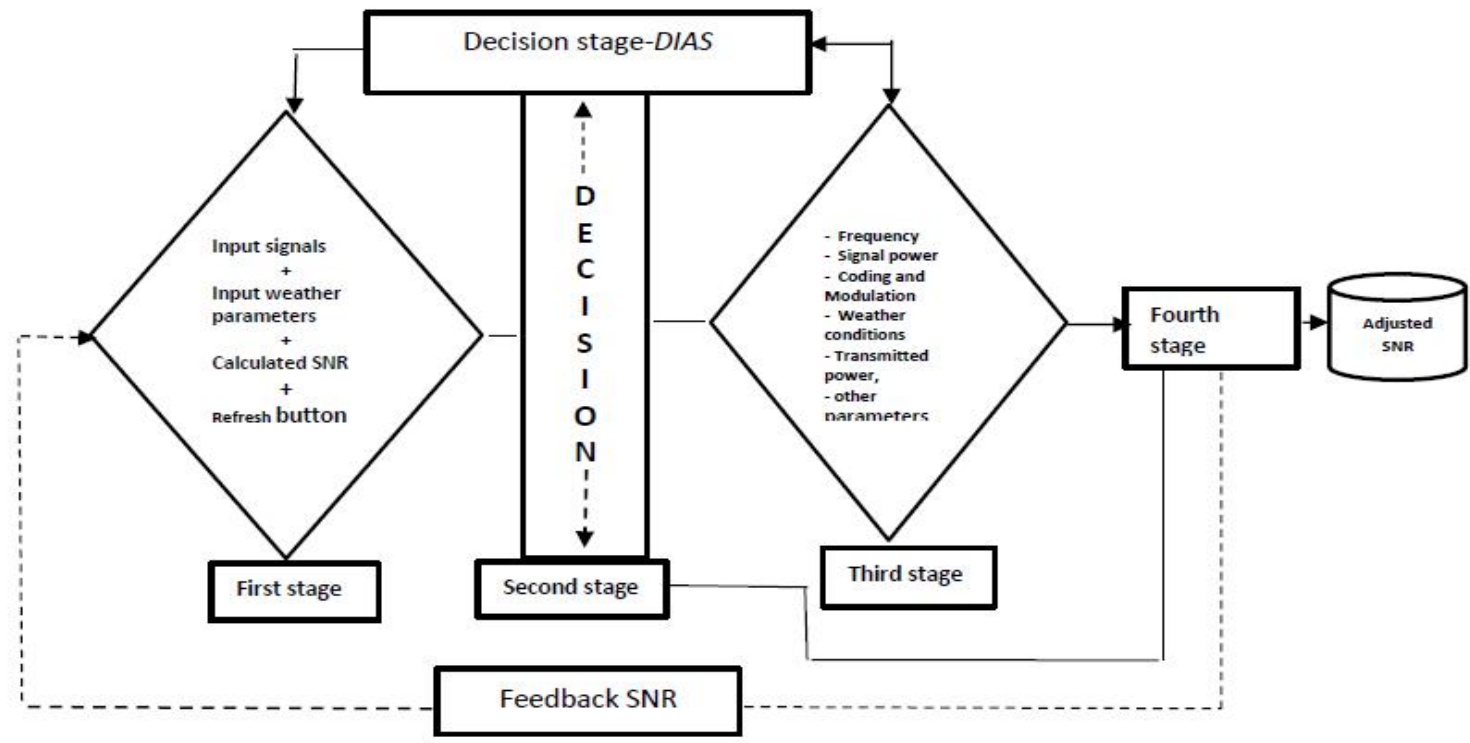

Fig. 2. DAIS algorithm for achieving good QoS.

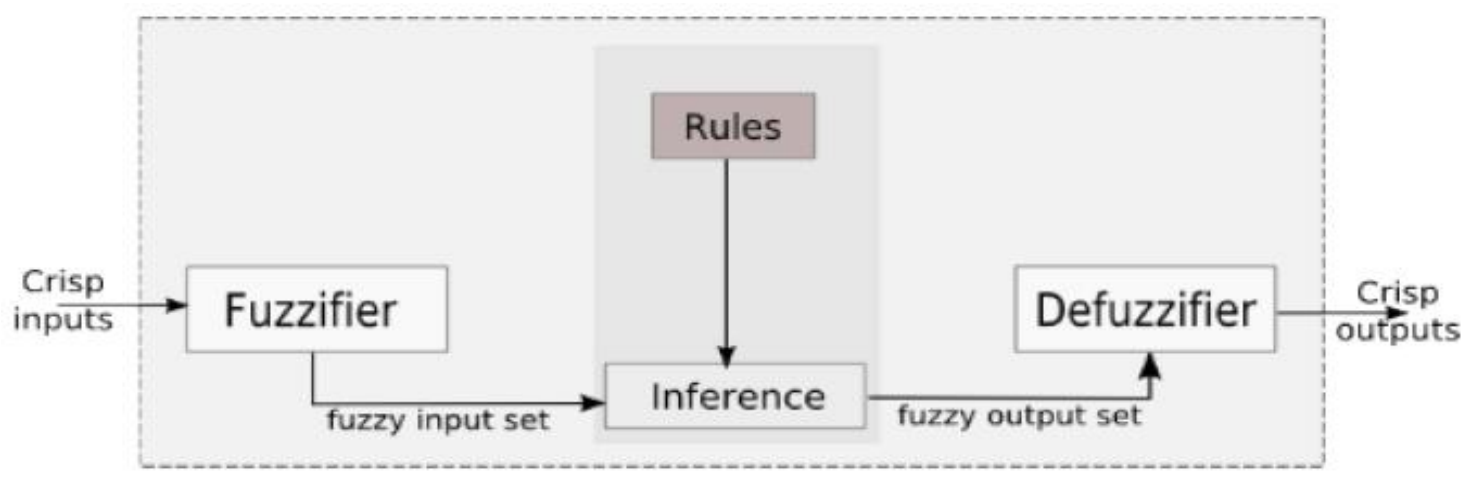

Fig. 3: Block diagram of the proposed description of the fuzzy rule scheme adopted for the DAIS.

\section{RESUlTS AND Discussion}

In this section, the results obtained in the analysis of rain rate and rain-induced attenuation over the study sites are first presented to ascertain the level of degradation that could be encountered along the earth-space propagation links by the main impairments factor-rain. We also considered the results of the total impairments on the propagation paths and the implication on a satellite system designing. The proposed DAIS is finally demonstrated and compared with various other parameters at each of the study sites through the simulations and the results are presented.

\section{A. Complimentary Cumulative Distribution Function (CCDF)}

Fig. 4 presents the comparison of CCDF of measured rain rate with the predictions of [29] for all the study locations and based on different time percentages, $p$ at equiprobable excedance probability between 0.001 and $3 \%(0.001 \% \leq p 3 \%)$. As indicated in Fig. 4, there is a good fit at time percentages $\geq 0.5 \%$ with low rain rates not more than $12 \mathrm{~mm} / \mathrm{hr}$ depending on the sites. However, as the time 
percentages become lower, considerable differences could be seen especially as we move from the Sahel region (Kano) to the coastal region of the country $(\mathrm{PH})$ with an average rain rate greater than 25 $\mathrm{mm} / \mathrm{hr}$.

The results of Fig. 4 also revealed that ITU model prediction shows a considerable difference significantly for the CCDF of rain rate even though the model gives a high level of agreement at higher equiprobable exceedance probability $p \geq 5 \%$ except in Kano. There is a gross underestimation from the measured rain rate values even at a higher time percentage in Kano. This might be due to the nature of the rain pattern in the locality which is different from other regions of the country as evidence in Table 1 . Specific results show that at $0.1 \%$ of the time, for example, the measured rain rates are about 47.2, 38.8, 36.6, 35, and $33.7 \mathrm{~mm} / \mathrm{hr}$ at PH, Akure, Ilorin, Zaria and Kano respectively, while the corresponding estimated values are $42.2,35.2,33.8,32.6$ and $21.1 \mathrm{~mm} / \mathrm{hr}$ respectively [29]. Also at $0.01 \%$ of the time, the measured rain rates are about 129.9, 106.6, 100.8, 96.4, and 92.8 $\mathrm{mm} / \mathrm{hr}$ at $\mathrm{PH}$, Akure, Ilorin, Zaria, and Kano respectively, and the corresponding ITU estimated values are 114.1, 94.4, 93.3, 91.6 and $77.8 \mathrm{~mm} / \mathrm{hr}$ respectively. The deviation between the measured and predicted values are even more pronounced at equiprobable exceedance probability $\mathrm{P} \leq 0.001 \%$. For instance, at PH site with the worst-case scenario of rain rate, the deviations are about 35 and 16 $\mathrm{mm} / \mathrm{hr}$ for 0.001 and $0.01 \%$ of the time, respectively, which underestimates the measured values by about $-16 \%$ and $-13 \%$ respectively based on relative error probability as recommended by [30].

The same trend could be observed in other locations although with different percentages of deviation. The higher percentage of deviation observed could be because the ITU model was derived based on data from the temperate region with little or no contribution from the tropical region, hence the need to use local data for rain attenuation prediction for this region.

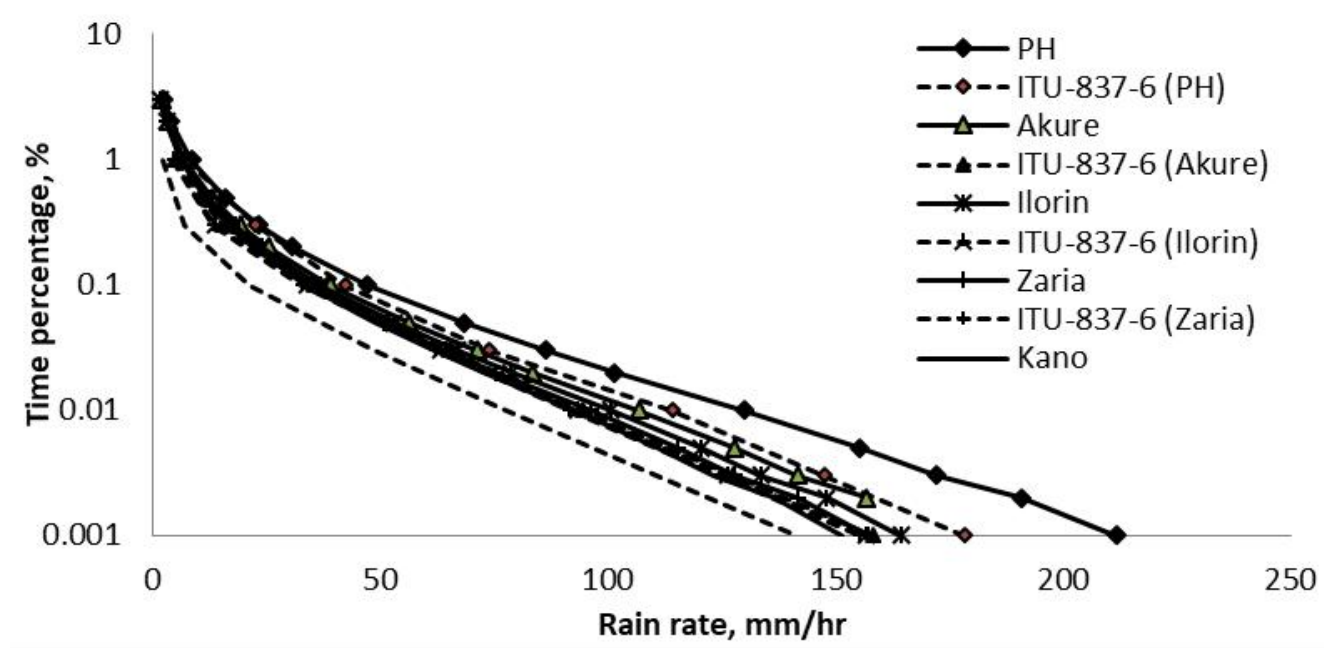

Fig. 4. Comparison of CCDF of measured rain rate with the predictions of ITU-R 837-6 (2012) for all the study locations.

The CCDF for the equivalent rain-induced attenuation at $12.245 \mathrm{GHz}$ and $21.751 \mathrm{GHz}$ compared with [20] based on equations (1) to (5) are also presented in Figs. 5 (a) and 5 (b) respectively. The attenuation has been obtained from both Eutelsat 36B (Ku-band) and Eutelsat 7A (Ka-band) as 
viewed from each of the sites. It is obvious from the two plots that rain-induced attenuation values are higher at Ka-band frequency when compared with Ku-band frequency. As depicted in Fig 5(a) for the Ku-band frequency, the measured rain-induced attenuation at $0.1 \%$ of the time is $7.3 \mathrm{~dB}, 6.1,5.7,5$, and $4.9 \mathrm{~dB}$ at $\mathrm{PH}$, Akure, Ilorin, Zaria, and Kano respectively.

In comparison, the predicted attenuations by the ITU model at $0.1 \%$ are $6.5,5.3,4.9,4.5$, and $4 \mathrm{~dB}$ respectively. These results indicated a good fit at this equiprobable exceedance probability with $\sim 1$ $\mathrm{dB}$ difference. However, at $0.01 \%$ of the time, the measured rain attenuation values are 15.9, 13.73, $13.2,12.6$, and $12 \mathrm{~dB}$, while at $0.001 \%$ of the time the values are $23.6,21.3,20.9,20.4$, and $20 \mathrm{~dB}$ over PH, Akure, Ilorin, Zaria, and Kano, respectively. Comparison with ITU model at $0.01 \%$ of the time shows attenuation values are $13.2,11.3,11,10.2$, and $9.2 \mathrm{~dB}$, while at $0.001 \%$, the values are 21.7, 19, 17.8, 17, and $16.8 \mathrm{~dB}$ over PH, Akure, Ilorin, Zaria, and Kano respectively. Although, these values have been underestimated, particularly at $0.001 \%$ of the time with about $3 \mathrm{~dB}$, yet, ITU-R model still closely agrees with the measurements based on the relatively lower deviation.

The same trend could be seen in Fig. 4 (b) for Ka-band, although with different values of raininduced attenuation. The overall results further collaborated early study by some researches carried out in the tropical region that the ITU rain attenuation model closely agrees with the point attenuation measurements when compared with other attenuation models [10]- [12], [31]-[33].
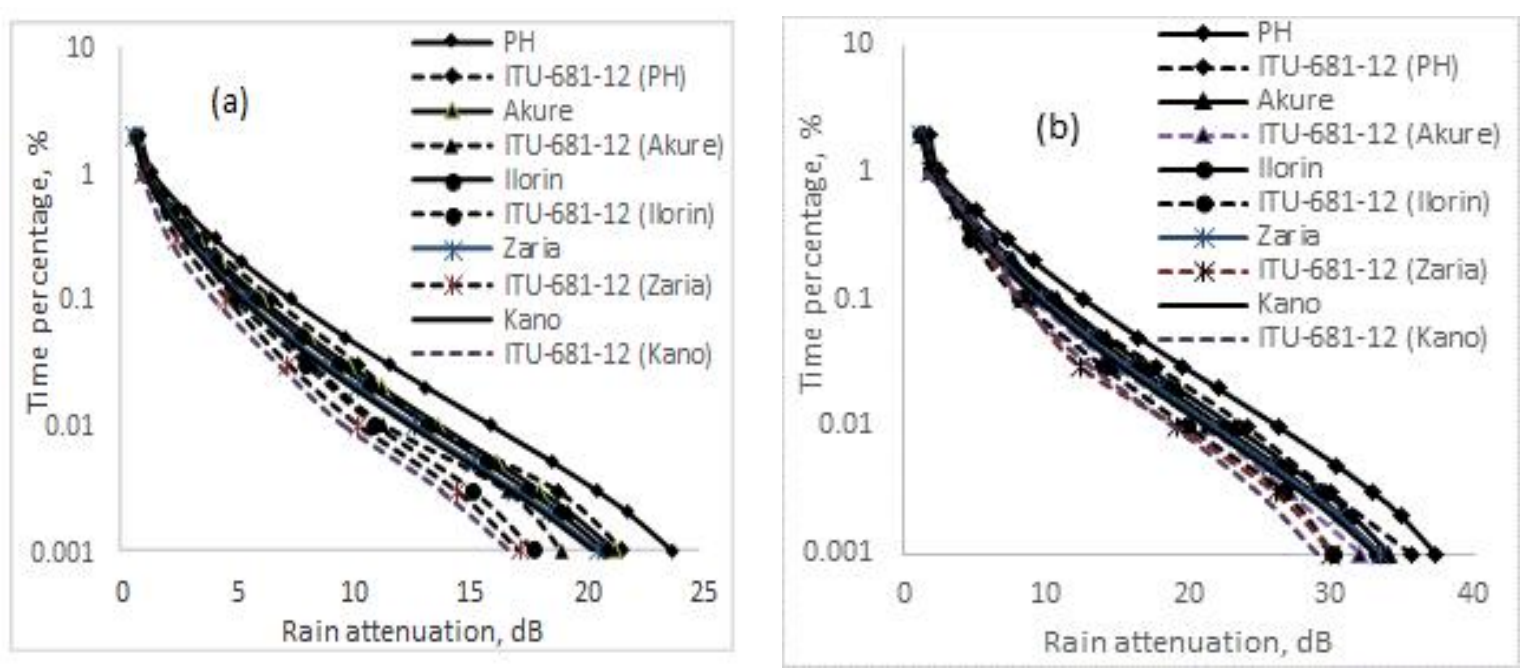

Fig. 5. Comparison of CCDF of measured rain attenuation for (a) 12. 245 and (b) $21.751 \mathrm{GHz}$.

\section{B. Influence of Total Impairments}

Based on the simulation that combined the individual propagation impairments affecting $\mathrm{Ku}$ to $\mathrm{V}$ band satellite links, Fig. 6 presents the influence of total impairments on propagation frequencies for equiprobable exceedance probability $0.1 \%<p \leq 0.01 \%$. It is worth mentioning that the total impairments due to the combined propagation factors decrease as one goes from the C-zone of the country, which is typified for high rain occurrence, cloud cover, melting layer, tropospheric 
scintillation, and gaseous absorption to the S-zone that is typified with lesser rain occurrence, cloud coverage, melting layer, tropospheric scintillation but with more dust particles. In general, the total impairments are lower in Ku-band frequency and higher in the V-band region.

Similarly, the total attenuation observed is lower at $99.9 \%$ signal availability but higher at $99.99 \%$ of signal availability. The implication is that for multimedia applications and data transmission, the $\mathrm{Ka}$ and V-band frequencies will be seriously degraded along the Earth-satellite propagation links even during clear sky conditions as a result of the contribution of tropospheric scintillation and other clear air effects. We also observed a significant increase in total impairments at frequencies $\geq 20$ $\mathrm{GHz}$ than at frequencies less than $20 \mathrm{GHz}$, this might be as a result of the contribution of other impairments like gaseous attenuation, melting layer, and cloud/fog to the total attenuation along the propagation links.

Figs. 7 (a-e) also depict the comparative plots between the total impairments and rain-induced attenuation at different frequencies for 0.1 and $0.01 \%$ of the time. It is obvious the contributions of other impairments at different frequencies in all the study locations. For example, in Fig. 7 (a) for PH at $0.1 \%$ of the time and frequencies between 12.245 and $40 \mathrm{GHz}$, the contribution due to total impairments ranges between 8.9 and $84.8 \mathrm{~dB}$ while contribution due to only rain-induced attenuation ranges between 7.3 and $74.7 \mathrm{~dB}$. This gives a difference up to $10 \mathrm{~dB}$ at the higher frequency band. Also at $0.01 \%$ of the time, the contribution due to the total impairments ranges between 17.7 and $143.6 \mathrm{~dB}$ while contribution due only to rain-induced attenuation alone ranges between 15.9 and $131.1 \mathrm{~dB}$, leading to about $13 \mathrm{~dB}$. The remaining studied sites follow same trend but with variances in $\mathrm{dB}$. The implication is that if the only attenuation due to rain is considered, the link budgeting might be underestimated and lead to system poor performance under bad weather conditions.

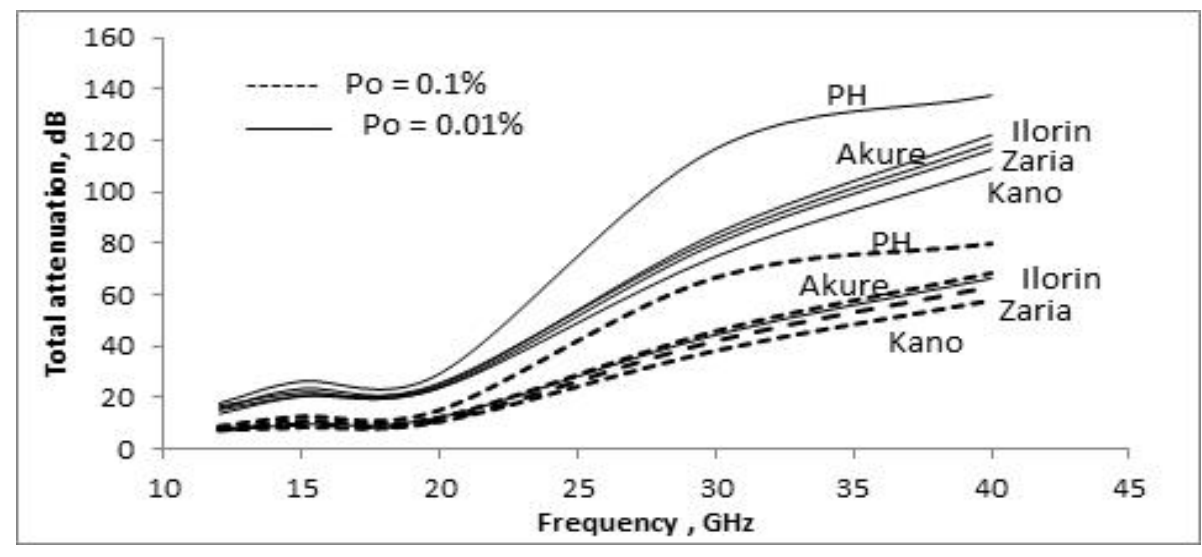

Fig. 6. Influence of total impairments on propagation frequencies for equiprobable excedance probability

$$
0.01 \%<P \leq 0.001 \% \text {. }
$$



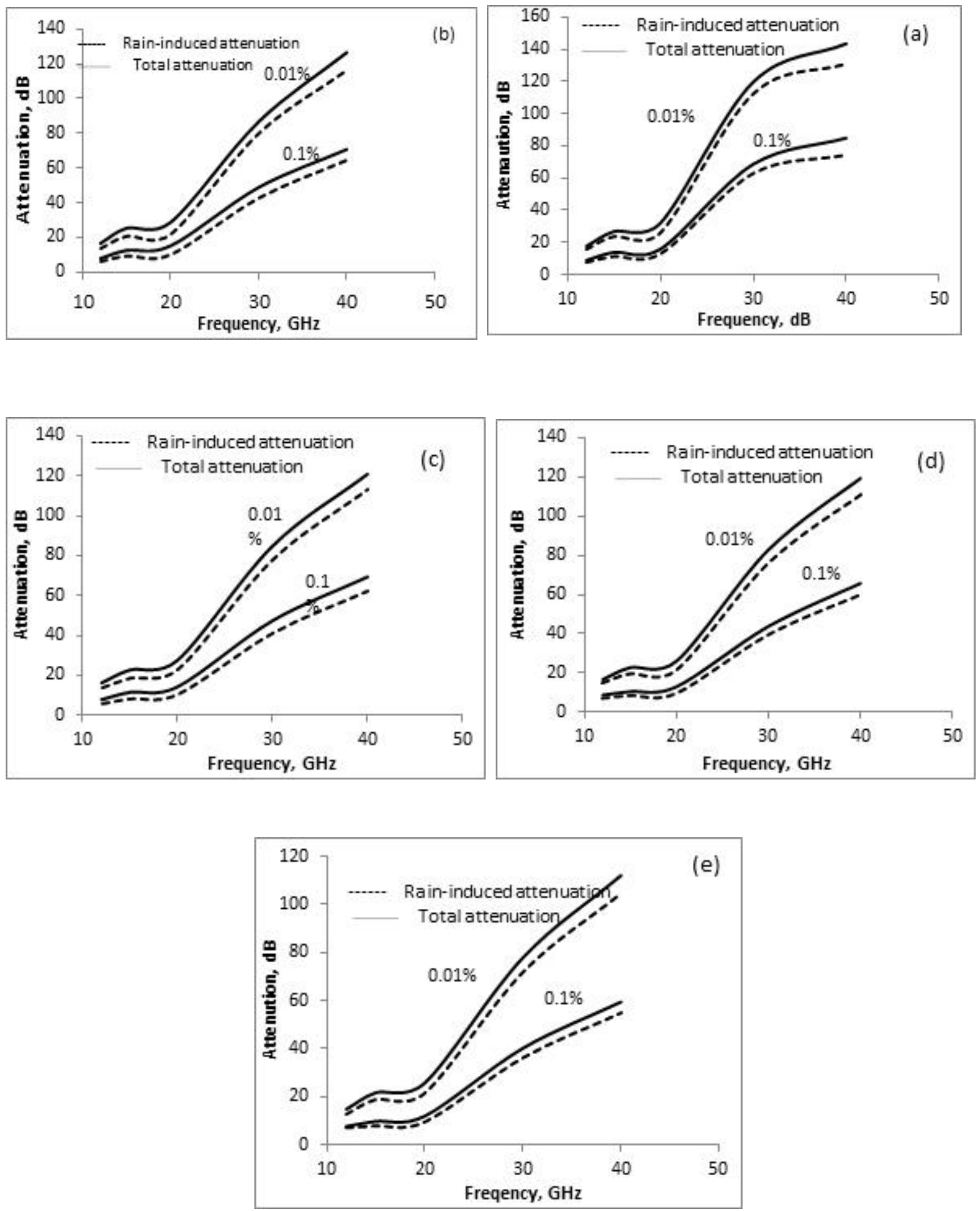

Fig. 7. Comparison of total impairments with rain-induced attenuation at different frequencies time for 0.01 and $0.1 \%$ of the time at (a) PH (b) Akure, (c) Ilorin, (d) Zaria and (e) Kano.

C. Estimated SNR based on $E_{b} / N_{o}$

We have adopted equations (7) to (10) to estimate SNR based on $E_{b} / N_{o}$ for applications on satellite system design. The probability that a satellite signal will be available in a year is defined as the percentage of the time in a year whereby the bit error ratio is lower than a given threshold value, 
beyond which a system outage can be experienced. Fig 8 presents the CCDF of $E_{b} / N_{o}$ slope for all the stations under-study for a QAM modulation scheme. The $E_{b} / N_{o}$ is presented for the Eutelsat $36 \mathrm{~B}-\mathrm{Ku}$ band, Eutelsat 7A- Ka-band configurations, and $40 \mathrm{GHz}$ frequency to take into account the V-band spectrum. It can be noticed that the higher the operating frequency, the noise power becomes higher than the signal power, and therefore the signal to noise ratio, in $\mathrm{dB}$, becomes negative. The implication is that for a given threshold signal, the probability to have relatively more signal fading based on $E_{b} / N_{o}$ slope values is higher for the V-band frequency configuration than for the Eutelsat $7 \mathrm{~A}$ and Eutelsat 36B configurations.

The trend also decreases as we move from the coastal region $(\mathrm{PH})$ to the Sahel region (Kano). For example, for the $21.751 \mathrm{GHz}$ frequency, the probabilities to have noise power greater than signal power are between equiprobable exceedance probabilities 0.03 and $0.01 \%$ at $\mathrm{PH}, 0.02$, and $0.01 \%$ at Akure, Ilorin, and Zaria, while it only occurred at $0.01 \%$ at Kano site. However, at $40 \mathrm{GHz}$ frequency, the equiprobable exceedance probability increased to a higher percentage of $0.1 \%$ at $\mathrm{PH}$ while being between 0.05 and $0.01 \%$ at the remaining stations. The implication is that at V-band frequency, the percentage probability to have noise power greater than signal power is about $55.6 \%$ for the $\mathrm{PH}$ site and about $44.4 \%$ for the rest of the study locations. This percentage is too high to be accommodated for good QoS and CSLAs; hence an algorithm is needed to enhance the QoS.

Figs. 9 ( $a$ and $b$ ) also present typical plots of BER estimated for four modulation schemes: QPSK, 16-QAM, 16-PSK, and 64-QAM at $21.751 \mathrm{GHz}$ and $40 \mathrm{GHz}$ frequency respectively. It can be seen that the more the number of bits per second based on the M-ary modulation scheme, the bits' error ratio increased simultaneously as the signal propagation traversed through the atmosphere. Under different propagation impairments, as the M-ary modulation scheme increases, so also the $B E R$ as a result of the higher number of transmitting bits in unit time [34]. It can generally be affirmed that since the lower SNR leads to lower $E_{b} / N_{o}$, and the lower $E_{b} / N_{o}$, leads to higher BER, hence, the higher the BER, the slower the effective data rate, and the lower the SNR, the slower the effective data rate.

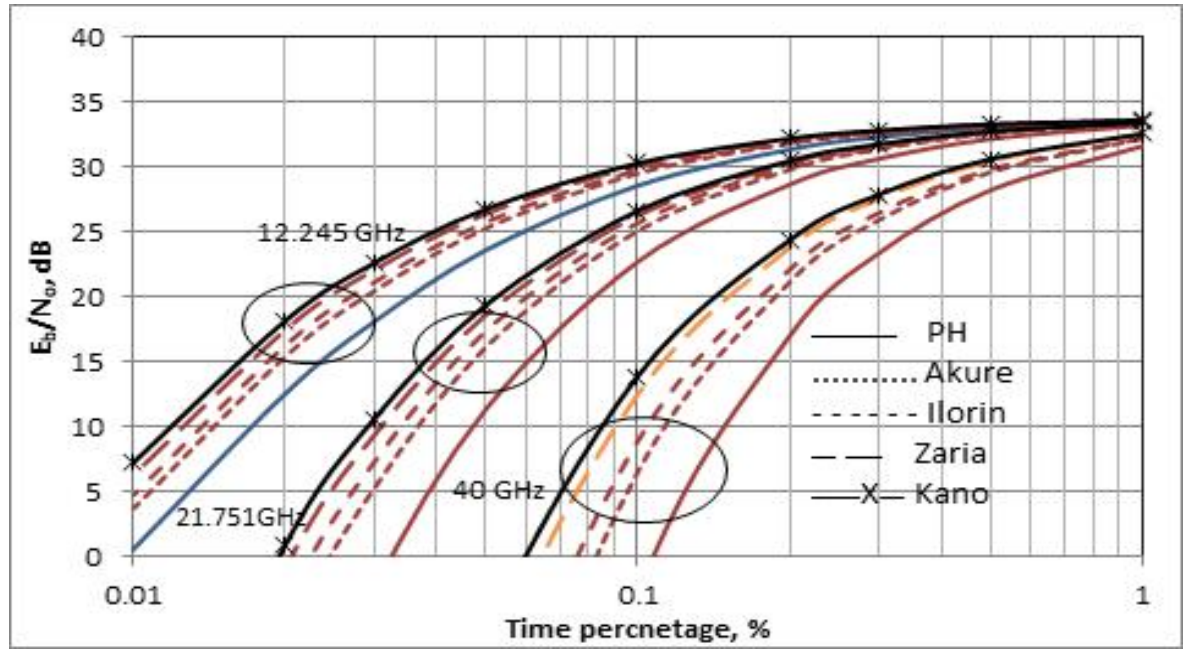

Fig. 8. Variation of CCDF of $E_{b} / N_{o}$ slope for a QAM modulation scheme at different frequencies. 

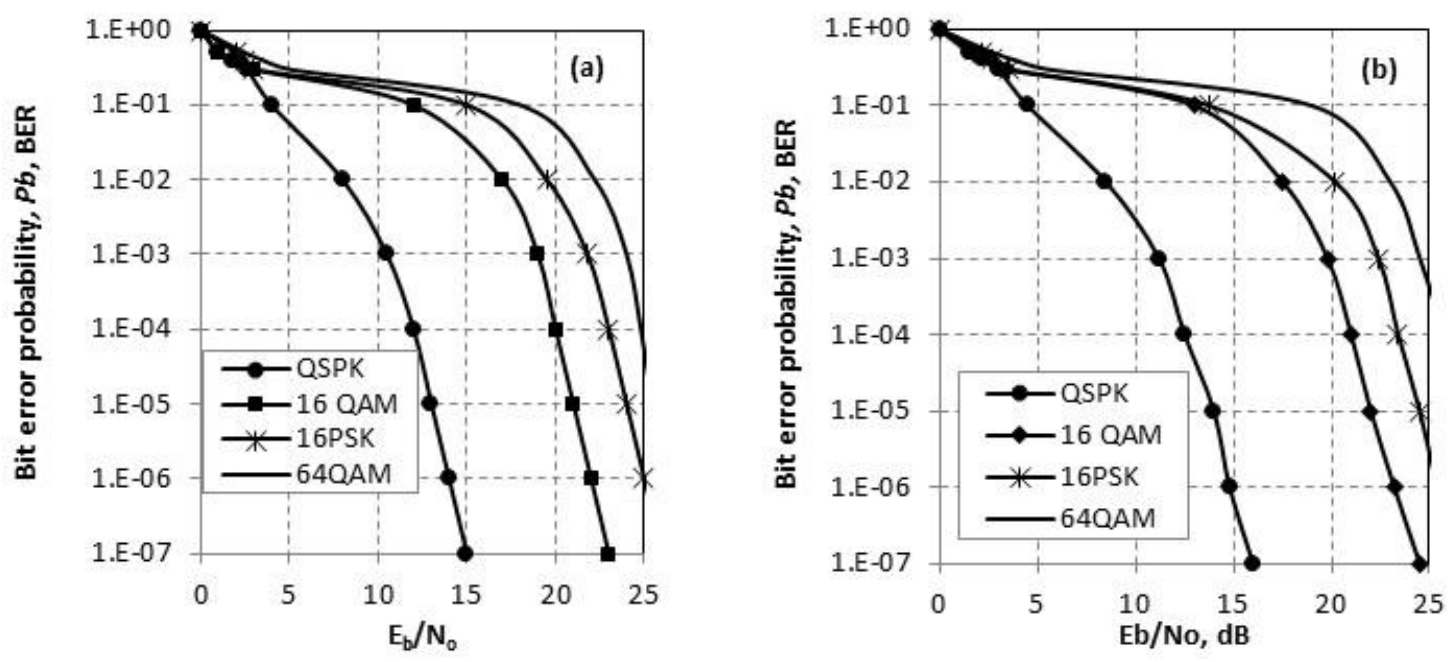

Fig. 9. Typical plots of BER estimated for four modulation schemes at (a) $21.751 \mathrm{GHz}$ and (b) $40 \mathrm{GHz}$.

\section{Simulation Output based on DIAS}

Based on the steps presented in section 2.3, we have adopted DAIS using the Fuzzy logic scheme over an AWGN channel following the algorithm depicted in Figs. 2 and 3. The input data was trained, checked, and tested to determine the error rate and validate the imputed data. The ANFIS generated 243 rules to control the SNR based on five membership functions for each of the imputed data. The results generated are a key tool for troubleshooting, regulating, and enhancing satellite transmitting power based on the appropriate coding and modulation schemes that are directed through an efficient algorithm-based total impairment controlled system. Many results are generated for each of the study sites; however, we initially presented results from the influence of the basic three parameters (total attenuation, propagation angle, and frequency) for all the sites and thereafter presented the worst-case scenario of the SNR and the enhanced SNR due to paucity of space. All results are presented in three dimensional (3D) forms.

\section{E. Influence of Total Attenuation and Propagation Angle on Frequency}

Figs. 10 (a-e) presents the output 3D plots on the influence of total impairments and propagation angles over different satellite propagation frequencies between 12.245 and $40 \mathrm{GHz}$ for $\mathrm{PH}$, Akure, Ilorin, Zaria, and Kano respectively. Generally speaking, as the satellite frequency increases along different propagation angles, the amount of total impairment in $\mathrm{dB}$ that could be encountered along the propagation path increases. It is also obvious that at propagation angle $\geq 30^{\circ}$, there are sudden rises in the total attenuation as a result of more contributions of the impairments, especially the cloud/fog, rain, gaseous absorption among others at higher frequency bands. Consequently, we observed a significant change in total attenuation as the satellite frequency changed for the same fixed angle of the satellite. For example, in Fig. 10 (a) for the PH site with the worst propagation impairments scenario, the total impairments from 10 to $50^{\circ}$ propagation angles varies between 8.2 and 99.6 dB at $12.245 \mathrm{GHz}$ Ku-band frequency, 15.3 and $118.8 \mathrm{~dB}$ at $21.751 \mathrm{GHz}$ Ka-band frequency, 15.6 and $122.1 \mathrm{~dB}$ at $30 \mathrm{GHz}$ uplink Ka-band frequency, and 17.7 and $137.5 \mathrm{~dB}$ at V-band 
frequencies. This same trend continues in other study sites, however with different values of total impairments. This result will help in system designing, especially in the area of the total impairments threshold needed for the link budgeting at different propagation angles of satellite services in Nigeria.
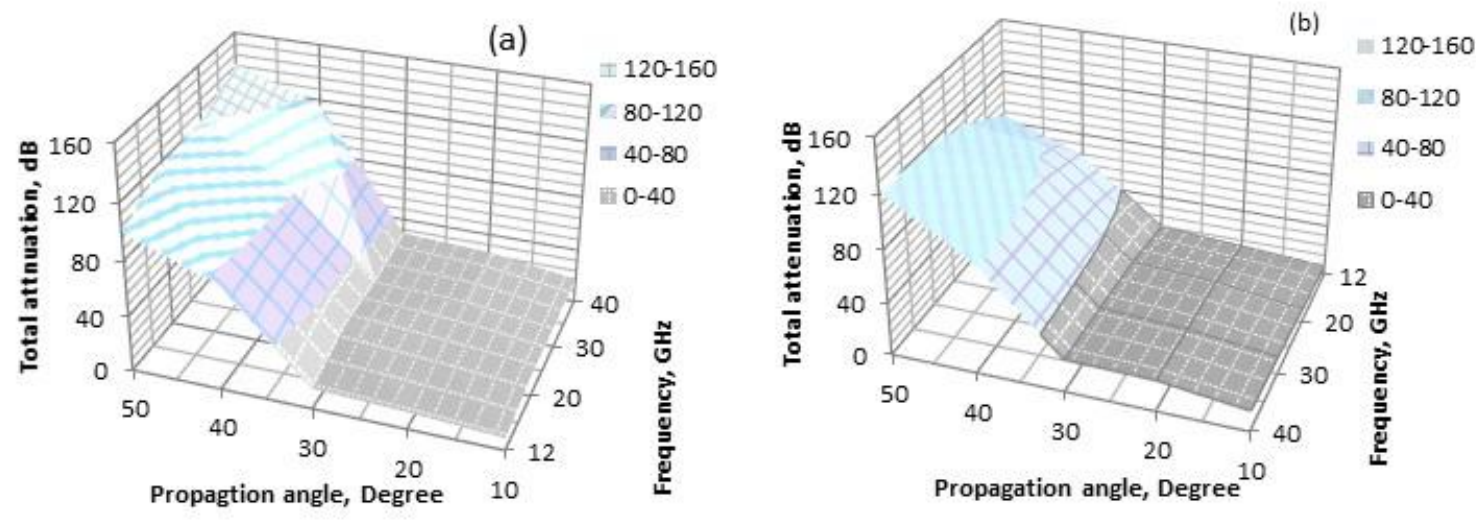

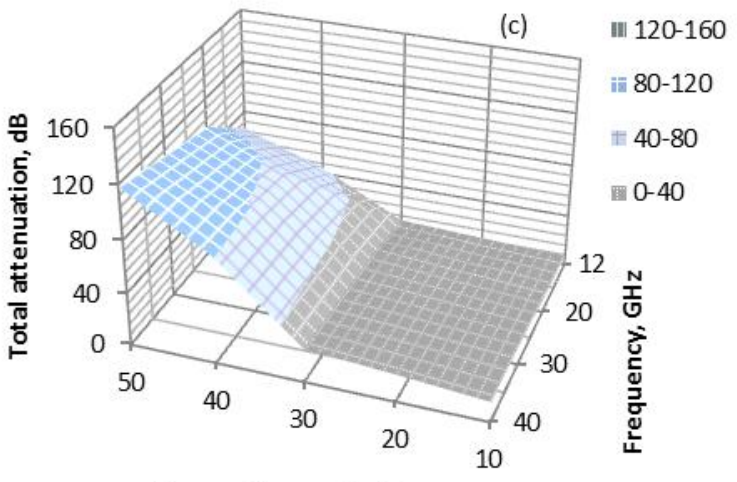

Propagation angle, Degree

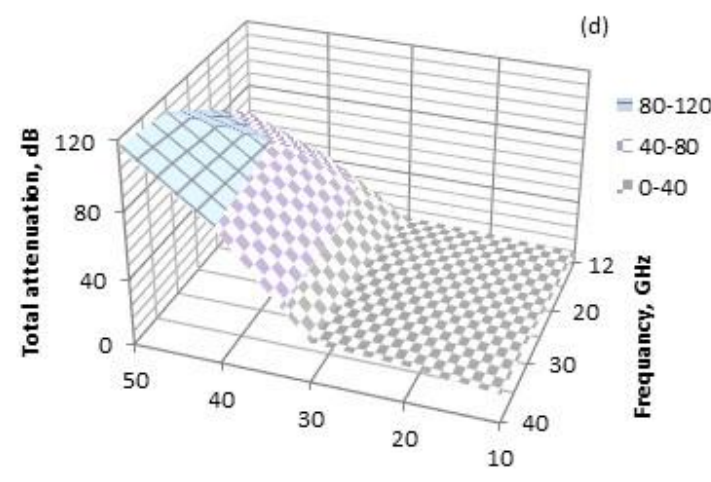

Propagation angle, Degree

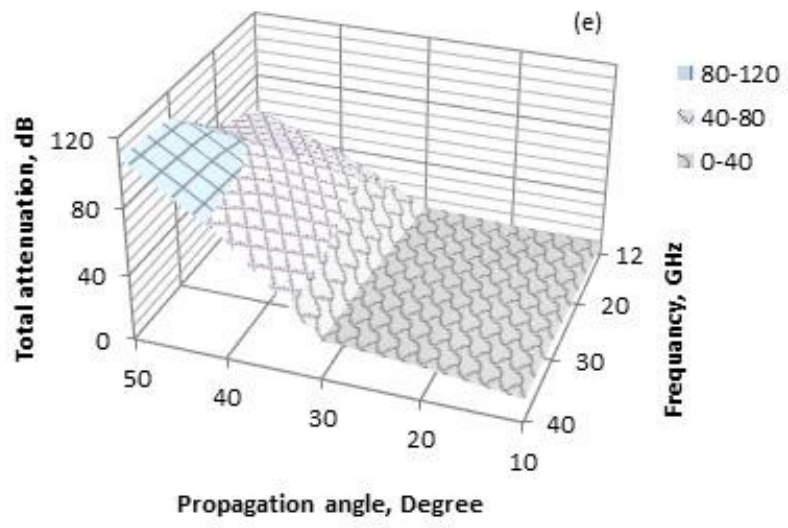

Fig. 10. Variation of total impairments and propagation angles at different satellite propagation frequencies between 12.245 and $40 \mathrm{GHz}$ for (a) PH (b) Akure (c) Ilorin (d) Zaria and (e) Kano.

\section{F. Influence of Total Attenuation and Transmitting Power on SNR}

Figs. 11 (a-c) also present typical results of the variation of total impairments and transmitting power on outputs SNR before enhancement for a worst-case scenario at 12. 245, 21.751, and $40 \mathrm{GHz}$ frequency respectively. Results are presented to establish the level of degradation that could be 
encountered along the satellite propagation links before adopting DAIS on the link. As depicted in Fig. 11 , as we increase the transmitting power between -80 and $-30 \mathrm{dBm}$, and the total impairments along the propagation paths, the SNR increases [17], [25]. The implication is that the noise power becomes much greater than the signal power as the total impairments increases. To be précised, at the preset transmitting power, the SNR produces between $\sim-66$ and $-36 \mathrm{~dB}, \sim-86$, and $-58 \mathrm{~dB}$ and $\sim-108$ and $48 \mathrm{~dB}$ at $\mathrm{Ku}, \mathrm{Ka}$ and, V-band frequencies respectively as indicated in Figs 11 (a-c).
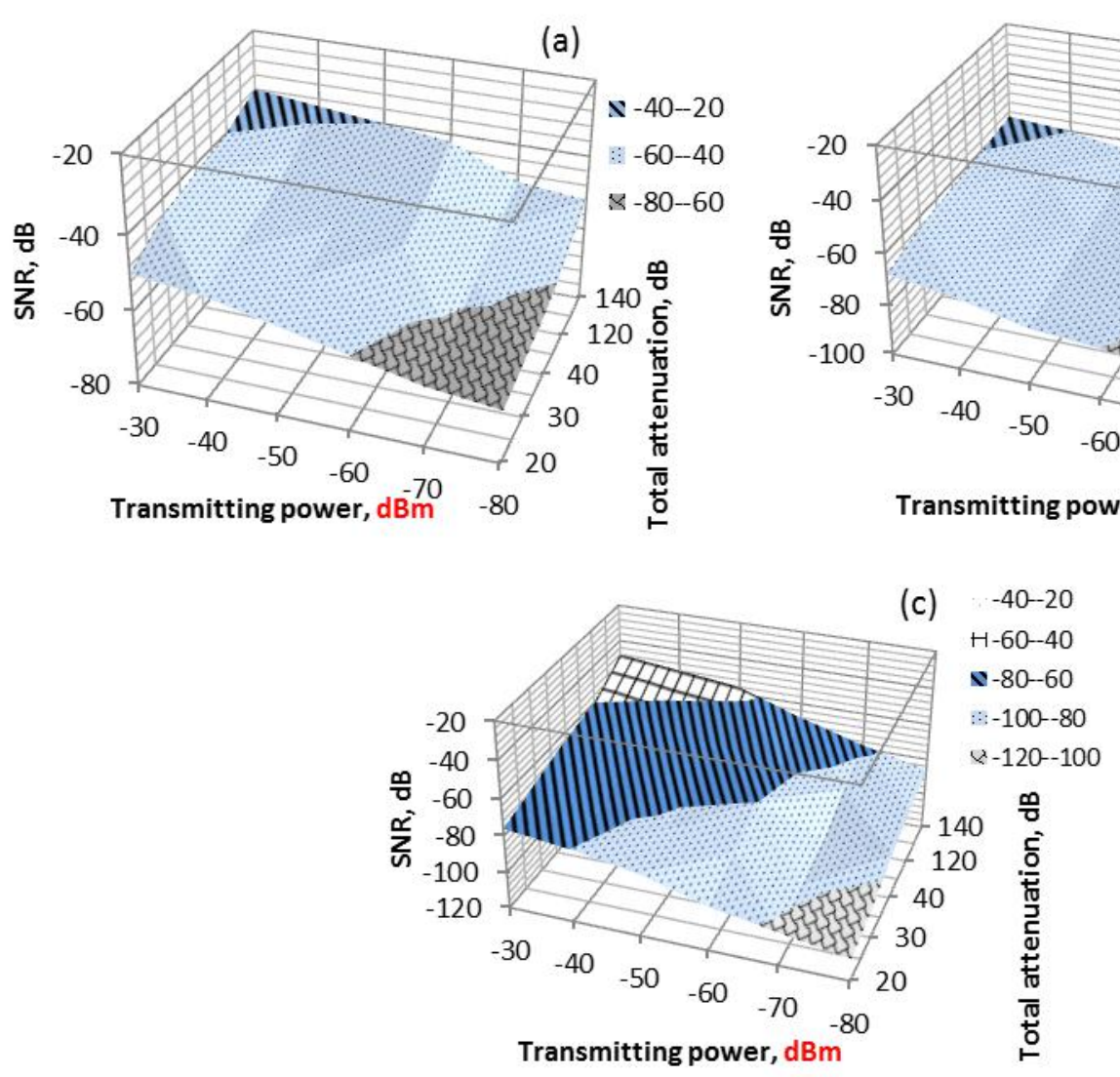

(b) $\quad-40-20$

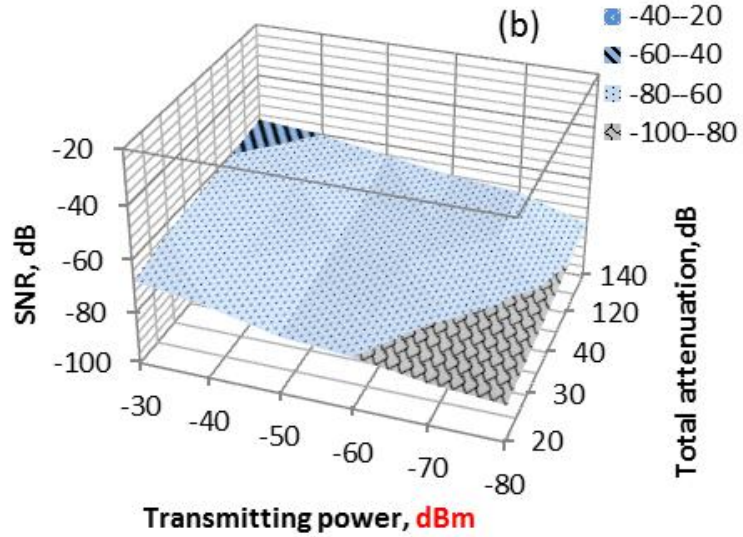

Transmitting power, $\mathrm{dBm}$

Fig. 11. Typical results of the variation of total impairments and transmitting power on outputs SNR before enhancement for a worst case scenario at (a) 12. 245 (b) 21.751 and (c) $40 \mathrm{GHz}$ frequency.

\section{G. Variation of Total Attenuation on Enhanced Transmitting Power and SNR}

We finally present results on the enhanced SNR and enhanced transmitting power output based on DAIS. Typical output results are presented in Figs 12 (a-c) for 12. $245 \mathrm{GHz}, 21.751 \mathrm{GHz}$, and $40 \mathrm{GHz}$ frequency respectively, for the same range of total impairments. The results show that by adopting the DAIS based on Fuzzy logic, the enhanced output SNR now ranges from $\sim-25$ to $16 \mathrm{~dB},-30$ to $22 \mathrm{~dB}$, -32 to $28 \mathrm{~dB}$ while the enhanced transmitting power now ranges between -26 to $-12 \mathrm{dBm},-32$ to $20 \mathrm{dBm}$ and -45 to $-30 \mathrm{dBm}$ for $12.245,21.751$, and $40 \mathrm{GHz}$ frequency respectively. The implication is that by adopting DAIS based on fuzzy logic we have been able to achieve a significant reduction in the transmit power by about $70 \%$ and SNR $50 \%$ across the frequencies considered 
without altering the information content of the downlink parameters thereby improving the QoS significantly and adhering to CSLAs irrespective of the weather dynamics.
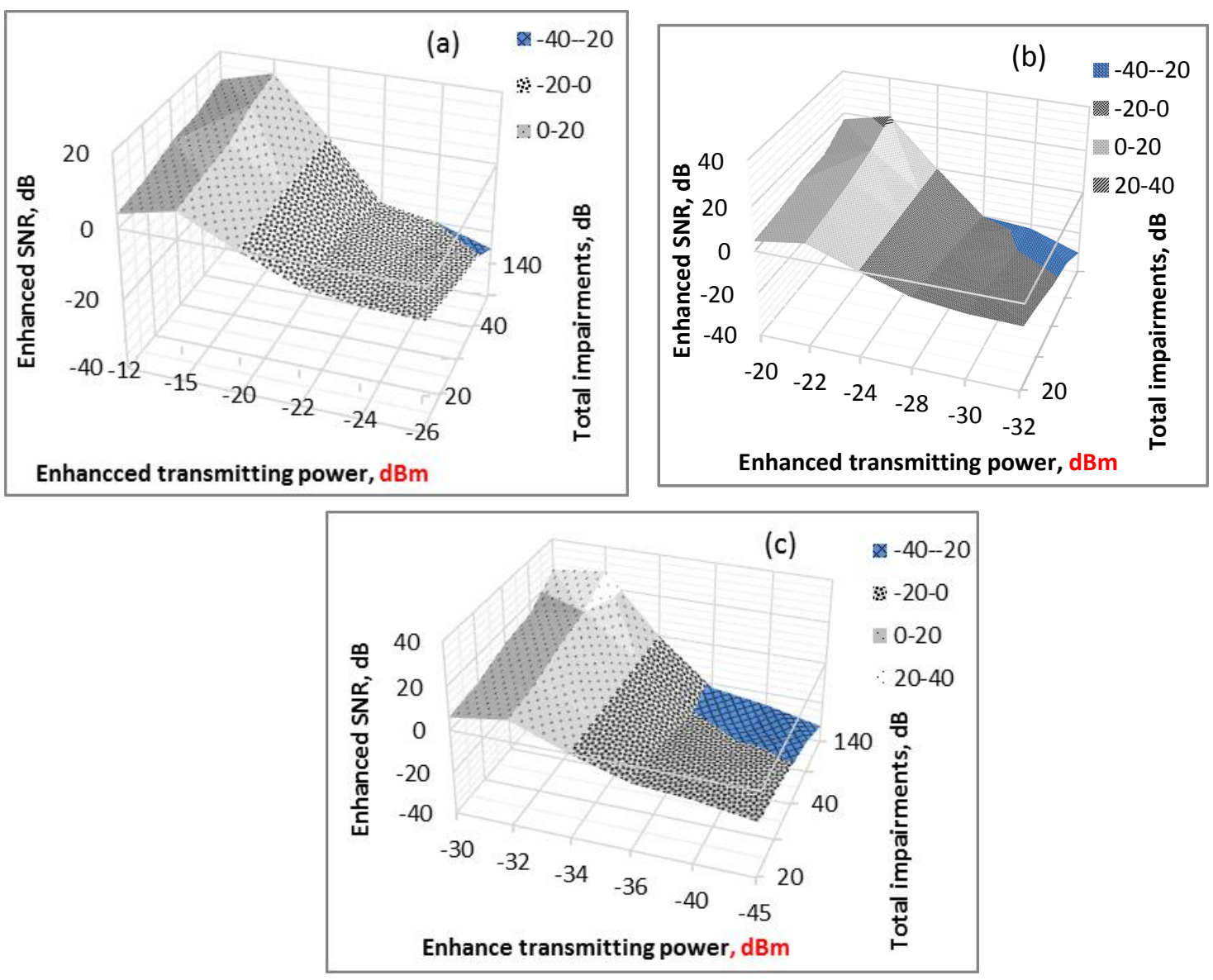

Fig. 12. Typical results of the variation of total impairments and enhanced transmitting power on enhanced SNR for a worst case scenario at (a) 12. 245 (b) 21.751 and (c) $40 \mathrm{GHz}$ frequency.

\section{CONCLUSION}

The increasing level of the satellite services to nearly all the sectors deserve significant improvement on the QoS rendered to the customers irrespective of the weather dynamics. In this paper, a dynamic adaptive intelligent scheme (DAIS) based on ANIFIS fuzzy logic has been proposed to contend with several propagation impairments along the Earth-space links in the tropical region. Individual impairments along the satellite propagation paths have been identified and simulated based on their combined effect. The influence of the propagation effects across Eutelsat 36B (Ku-band), Eutelsat 7A (Ka-band), and V-band frequency satellite coverage areas over Nigeria were examined to deduce the system optimization that can potentially be adopted based on local data with high spatial resolution. The proposed algorithm troubleshoots, adjusts, and enhanced satellite transmitting power, based on appropriate coding and modulation schemes that are directed to the dynamically combined impairments along the satellite propagation paths. 
The results of the comparison between total impairments and rain-induced attenuation alone lead to about $13 \mathrm{~dB}$ difference and if not accommodated can lead to underestimation of link budgeting in the area if only rain-induced attenuation is considered. The results before adopting the proposed algorithm show that, at V-band frequencies, the percentage probability to have noise power greater than signal power is about $55.6 \%$ for the $\mathrm{PH}$ site and about $44.4 \%$ for the rest of the study locations. This percentage is too high to be accommodated for good QoS and CSLAs, hence the justification to enhance the QoS in the area. Adopting DAIS based on fuzzy logic was able to achieve significant transmit power reduction by about $70 \%$ and SNR by $50 \%$ across the frequencies considered without altering the information content of the downlink parameters thereby improving the QoS significantly and adhered to SLAs irrespective of the weather dynamics. The results will enable satellite system designers to appropriate the accurate technique needed to counter the atmospheric impairments during weather dynamics in the area. The results also show that the ITU-R Rec. P681-12, which is a global method, is still adjudged suitable for predicting total attenuation in the tropical regions.

\section{ACKNOWLEDGEMENTS}

The authors wish to acknowledge the Nigerian Meteorological Agency for the data used in this work.

\section{REFERENCES}

[1] R. Z. Dhafer and S. A. A. A. W. Thulfiqar, "Simplified the QoS Factor for the Ad-Hoc Network Using Fuzzy Technique," International Journal of Communications, Network and System Sciences, Vol. 06No.09, p. 7, 2013.

[2] R. K. Crane, "Prediction of the Effects of Rain on Satellite Communication Systems," Proceedings of the IEEE, vol. 65, pp. 456-474, 1977.

[3] L. J. Ippolito, "Propagation Effects and System Performance Considerations for Satellite Communications above 10 Ghz," in in Proceedings of IEEE Global Telecommunications Conference and Exhibition GLOBECOM '90, 1990, pp. 89-91 vol.1.

[4] K. Harb, C. Huang, A. Srinivasan, and B. Cheng, "Intelligent Weather Aware Scheme for Satellite Systems," in 2008 IEEE International Conference on Communications, 2008, pp. 1930-1936.

[5] J. S. Ojo and P. A. Owolawi, "Estimation of the Propagation Impairments of Satellite Systems Design in the SHF and EHF Bands in Subtropical Region," Journal of Microwave Power and Electromagnetic Energy, vol. 49, pp. 147-159, 2015/01/01 2015.

[6] J. S. Ojo, "Analysis of Dynamical Rain Duration and Return Periods for Terrestrial and Satellite Communication Applications in a Tropical Climate," International Journal of Scientific \& Engineering Research, vol. 7, pp. 1305-1310, 2016.

[7] G. O. Ajayi and I. E. Owolabi, "Rainfall Parameters from Disdrometer Dropsize Measurements at a Tropical Station," Ann. Telecomm., vol. 42, pp. 3-12, 1987.

[8] R. K. Crane, Electromagnetic Wave Propagation through Rain: Wiley New York, 1996.

[9] A. Dissanayake, J. Allnutt, and F. Haidara, "A Prediction Model that Combines Rain Attenuation and other Propagation Impairments along Earth-Satellite Paths," IEEE Transactions on Antennas and Propagation, vol. 45, pp. 1546-1558, 1997.

[10] J. S. Ojo, M. O. Ajewole, and S. K. Sarkar, "Rain rate and Rain Attenuation Prediction for Satellite Communication in $\mathrm{Ku}$ and Ka bands over Nigeria," Progress In Electromagnetics Research B, vol. 5, pp. 207-223, 2008.

[11] J. S. Mandeep, "Rain Attenuation Statistics over a Terrestrial Link at $32.6 \mathrm{GHz}$ at Malaysia," IET Microwaves, Antennas \&amp; Propagation, vol. 3, pp. 1086-1093, 2009.

[12] S. Shrestha and D. Choi, "Study of Rain Attenuation in Ka band for Satellite Communication in South Korea," Journal of Atmospheric and Solar-Terrestrial Physics, vol. 148, pp. 53-63, 2016/10/01/ 2016.

[13] B. Vallamsundar, J. Zhu, K. Ponnambalam, C. Huang, A. Srinivasan, and B. Cheng, "Congestion Control for Adaptive Satellite Communication Systems using Intelligent Systems," in 2007 International Symposium on Signals, Systems and Electronics, 2007, pp. 415-418.

[14] C. Capsoni, F. Fedi, C. Magistroni, A. Pawlina, and A. Paraboni, "Data and Theory for a New Model of the Horizontal Structure of Rain Cells for Propagation Applications," Radio Science, vol. 22, pp. 395-404, 1987.

[15] Y. Karasawa and T. Matsudo, "Characteristics of Fading on Low-Elevation Angle Earth-Space Paths with Concurrent Rain Attenuation and Scintillation," IEEE Transactions on Antennas and Propagation, vol. 39, pp. 657-661, 1991. 
[16] K. Harb, A. Srinivasan, H. Changcheng, and B. Cheng, "Prediction Method to Maintain QoS in Weather Impacted Wireless and Satellite Networks," in 2007 IEEE International Conference on Systems, Man and Cybernetics, 2007, pp. 4008-4013.

[17] I. Adegbidin, P. A. Owolawi, and M. O. Odhiambo, "Intelligent Weather Awareness Technique for Mitigating Propagation Impairment at SHF and EHF Satellite Network System in a Tropical Climate," Research Journal of the South African Institute of Electrical Engineers, vol. 107, pp. 136 - 145, 2016.

[18] J. S. Ojo and P. A. Owolawi, "Prediction of Time-series Rain Attenuation based on Rain Rate using Synthetic Storm Techniques over a Subtropical Region," In Proceedings, Southern Africa Telecommunication Networks and Applications (SATNAC-2014) at Boardwalk, Port Elizabeth, Eastern Cape, South Africa, 31 August - 3 September, 2014, pp. $67-71,2014$.

[19] ITU-Rec.P.618-12, "Propagation Data and Prediction Method required for the Design of Earth-Space Telecommunication Systems," Radio Wave Propagation, International Telecommunication Union, Recommendation ITU-R P.618-12, 2015.

[20] ITU-Rec.P.618-13, "Propagation Data and Prediction Method required for the Design of Earth-Space Telecommunication Systems," Radio Wave Propagation, International Telecommunication Union, Recommendation ITU-R P.6I8-13, 2017.

[21] ITU-Rec.P.838-3, "Specific Attenuation Model for Rain for use in Prediction Methods," Radio Wave Propagation, International Telecommunication Union, Recommendation ITU-R P.838-3, 2005.

[22] ITU-Rec.P.676-10, "Attenuation by Atmospheric Gases," Radio Wave Propagation, International Telecommunication Union, Recommendation ITU-R P. 676-10, 2013.

[23] ITU-Rec.P.840-6, "Attenuation due to Clouds and Fog," Radio Wave Propagation, International Telecommunication Union, Recommendation ITU-R P.840-6, 2013.

[24] E. Lutz, M. Werner, and A. Jahn, Satellite Systems for Personal and Broadband Communications. New York: Springer, 2000.

[25] K. Harb, O. Butt, S. Abdul-Jauwad, and A. M. Al-Yami, "Systems Adaptation for Satellite Signal under Dust, Sand and Gaseous Attenuations," Journal of Wireless Networking and Communications, vol. 3, pp. 39-49, 2013.

[26] A. M. Al-Saegh, A. Sali, J. S. Mandeep, A. Ismail, A. H. J. Al-Jumaily, and C. Gomes, "Atmospheric Propagation Model for Satellite Communications," in MATLAB Applications for the Practical Engineer, K. Bennett, Ed., ed Croatia: Intech, 2014, pp. 249-275.

[27] DVB-Calculator. http://www.satellite-calculations.com/Satellite/Downlink.htm accessed 25 June, 2017. [Online].

[28] A. Gusmao, R. Dinis, J. Conceicao, and N. Esteves, "Comparison of Two Modulation Choices for Broadband Wireless Communications," in VTC2000-Spring. 2000 IEEE 51st Vehicular Technology Conference Proceedings (Cat. No.00CH37026), 2000, pp. 1300-1305 vol.2.

[29] ITU-Rec.P.837-6, "Characteristics of Precipitation for Propagation Modelling," Radiowave Propagation Series, International Telecommunication Union, Recommendation ITU-R P.837-6, 2012.

[30] ITU-Rec.P.311-15, "Acquisition, Presentation and Analysis of Data in Studies of Tropospheric Propagation," Radio Wave Propagation, International Telecommunication Union, Recommendation ITU-R P.311-15 2013.

[31] J. S. Ojo, M. O. Ajewole, and L. D. Emiliani, "One-Minute Rain-Rate Contour Maps for Microwave-CommunicationSystem Planning in a Tropical Country: Nigeria," Antennas and Propagation Magazine, IEEE, vol. 51, pp. 82-89, 2009

[32] J. S. Ojo and P. A. Owolawi, "Application of Synthetic Storm Technique for Diurnal and Seasonal Variation of Slant Path Ka-Band Rain Attenuation Time Series over a Subtropical Location in South Africa," International Journal of Antennas and Propagation, vol. 2015, p. 474397, 2015/01/05 2015.

[33] U. Kesavan, A. R. Tharek, and M. D. Rafiqul-Islam, "Rain Attenuation Prediction using Frequency Scaling Technique at Tropical Region for Terrestrial Link," Progress in Electromagnetics Research Symposium,Taipei, March, 25-28, 2013.

[34] A. Al-Saegh, A. Sali, J. Mandeep, A. Ismail, A. Al-Jumaily, and C. Gomes, "Atmospheric Propagation Model for Satellite Communications," in MATLAB Applications for the Practical Engineer, K. e. Bennett, Ed., ed, 2014. 